\title{
Segunda Residência na dinâmica urbana e turística da cidade de Portalegre (Rio Grande do Norte/RN, Brasil)
}

\section{Second-home in the urban and tourist dynamics of the Portalegre municipality (Rio Grande do Norte / RN, Brazil)}

\author{
Antonio Jaldesmar da Costa (COSTA, A. J. da) ${ }^{*}$ \\ Rosa Maria Rodrigues Lopes (LOPES, R. M. R.) \\ João Freire Rodrigues (RODRIGUES, J. F.) ${ }^{* * *}$
}

\begin{abstract}
RESUMO - O presente artigo objetiva analisar a influência da segunda residência na dinâmica urbana e turística da cidade de Portalegre (Rio Grande do Norte/RN, Brasil). O estudo inicia com um breve histórico sobre a temática, discutindo, os objetivos específicos que serão direcionados para composição dos aspectos históricos e teóricos sobre Segunda Residência e as mudanças no espaço urbano e turístico em decorrência da instalação destas, neste município. A pesquisa com metodologia descritiva analítica e abordagem quali-quantitativa, foi norteada através de entrevistas com os representantes do Poder Público e loteamento Varandas da Serra, e formulários semiestruturados aplicados com os turistas de segunda residência durante os finais de semana. Vale salientar, que a temática mereceu ser aprofundada devido os poucos estudos na área, principalmente direcionados a segunda residência em cidades serranas potiguares. Através das pesquisas em campo, os resultados apontaram para o fato de que o turismo contribuiu de forma efetiva para o crescimento das segundas residências, e, consequentemente para o aumento da valorização do uso do solo e ampliação da demanda por equipamentos e serviços urbanos. No entanto, percebeu-se que após o ano de 2012, as ações aconteceram de forma limitada, tendo em vista as precárias condições financeiras por parte do Poder Público. Ainda assim, os turistas estavam optando pelo município, motivados principalmente, pelas amenidades naturais que justificam uma melhor tranquilidade para momentos de descanso. Portanto, entende-se que a cidade estava dispondo de uma diversidade de elementos naturais, urbanos e turísticos,
\end{abstract}

\footnotetext{
* Formação: Graduação em Turismo pela Universidade do Estado do Rio Grande do Norte (UERN); Técnico em Guia de Turismo pelo Instituto Federal de Educação, Ciência e Tecnologia do Rio Grande do Norte (IFRN); Especialização em Gestão e Estratégica de Marketing pela Faculdade Internacional Signorelli (FISIG) e Mestrando em Planejamento e Dinâmicas Territoriais do Semiárido (Plandites/UERN). Atividade profissional: Coordenador Municipal de Turismo, Eventos e Lazer na Prefeitura Municipal de Riacho da Cruz - RN. Endereço físico para correspondência: Avenida Boa Vista, 950, Centro. CEP: 59.820-000 - Riacho da Cruz - RN/Brasil. E-mail: jaldesmar_cdi@hotmail.com

** Formação: Bacharelado e Licenciatura em Geografia; Mestrado em Geografia, ambos pela Universidade Federal do Rio Grande do Norte (UFRN); Doutorado em andamento em Programa de PósGraduação e Pesquisa em Geografia (UFRN). Endereço físico para correspondência: Rua Almino Afonso, s/n, Centro. CEP: 59.610-210 - Mossoró - RN/Brasil. E-mail: rosamrlopes@ gmail.com

*** Formação: Graduação em Ciências Sociais pela Universidade do Estado do Rio Grande do Norte (UERN); Mestrado em Sociologia pela Universidade Federal de Pernambuco (UFPE) e Doutorado em Ciências Sociais pelo Instituto de Ciências Sociais da Universidade de Lisboa. Atividade profissional: Professor adjunto IV da Universidade do Estado do Rio Grande do Norte, Mossoró/RN. Endereço físico para correspondência: Av. Prof. Antônio Campos, s/n, Costa e Silva. CEP: 59.600-900 - Mossoró RN/Brasil. E-mail: jrfreirerodrigues@gmail.com
} 
favorecendo o crescimento do turismo e das segundas residências e acentuando a dinâmica urbana local.

Palavras-chave: Turismo; Espaço Urbano; Segunda Residência.

ABSTRACT - This article aims to analyze the influence of the second-home on the urban and tourist dynamics of the Portalegre municipality (Rio Grande do Norte / RN, Brazil). The study begins with a brief history about the subject, discussing the specific objectives that will be directed to the composition of historical and theoretical aspects about second-homes and the changes in the urban and tourist space as a result of the installation of these in this municipality. The data research with analytical descriptive methodology and qualitative-quantitative approach was guided through interviews with representatives of the Government and Varandas da Serra development, and semistructured interviews were conducted with the tourists of second-home on weekends. It's worth emphasizing that a thematic deserved to be deepened due to the low studies in the area, mainly directed to the second-homes in potiguares mountainous cities. Through the field research, the results pointed to the fact that tourism contributed effectively to the growth of second-homes and consequently to increase the use of land and the demand for urban equipment and services. However, it's clear that after 2012, the actions happened by a limited way, considering the precarious financial conditions on the part of the Government. Still, tourists were opting for the municipality, mainly motivated by the natural amenities, which justify a better tranquility for moments of rest. Therefore, it's understood that the city was having a diversity of natural, urban and tourist elements, favoring the growth of tourism and the second-homes and accentuating the local urban dynamics.

Key words: Tourism; Urban Space; Second Home. 


\section{INTRODUÇÃO}

O turismo é uma atividade que estabelece inter-relações com os vários sistemas que compõem a sociedade e para que uma localidade desperte o interesse do turista, ela tem que ter um diferencial, certa singularidade que a diferencie das demais. Neste sentido, surgiu o interesse de estudar sobre os aspectos turísticos de Portalegre (Rio Grande do Norte/RN, Brasil), tendo como base o desenvolvimento das segundas residências e sua capacidade de contribuição com uma nova configuração urbana e turística da localidade receptora.

Para tanto, procurou-se entender os fundamentos teóricos da segunda residência, além de verificar a atuação desse segmento no processo de desenvolvimento urbano e turístico da cidade. Com este estudo se discutirá sobre a relevância e os benefícios das Segundas residências, voltadas ao desenvolvimento turístico nesta localidade. Marcada por diversas particularidades históricas, culturais e naturais, com uma população que tem traços marcantes da presença negra, sob o processo de miscigenação e ocupação de seu solo, constata-se que Portalegre tem o branco colonizador e o índio dizimado seus atores principais. "A cidade constitui-se em um dos primeiros municípios formados durante o processo de colonização do Brasil, demonstrando sua relevância na historiografia potiguar e brasileira" (CASCUDO, 1984).

O município de Portalegre - RN em estudo, está situado no Alto Oeste Potiguar, na chamada "Tromba do Elefante", porção central da Microrregião Serrana do RN, a uma distância da capital do estado de $366 \mathrm{Km}$, por via rodoviária, e possui uma área territorial de $110 \mathrm{~km}^{2}$ e uma população de 7.708 habitantes, tendo uma taxa de urbanização de 49,4\% (IBGE, 2010, p. 2).

De acordo com os dados acima citados, contata-se que o município de Portalegre é caracterizado pela atividade agrícola de subsistência, comercial e turística. Esta última é responsável por contribuir com o aumento do Produto Interno Bruto - PIB gerado no setor de serviços, já que a cidade dispõe de muitos atrativos culturais, históricos e naturais que atraem os visitantes e turistas que buscam sair da rotina dos grandes centros agitados.

A mudança no espaço turístico da cidade é referente a construção e usufruto de casas de segunda residência, intensificando seu uso no período da alta estação, feriados 
e finais de semana. Ressalta-se que essas transformações no município têm como prérequisito a existência do turismo. Um fator perceptível diz respeito ao surgimento de serviços imobiliários empenhados na promoção, comercialização e financiamento de loteamentos de condomínios, evidenciando uma diversificação do negócio imobiliário articulado ao turístico. Assim, levando em consideração o que foi apresentado anteriormente questionou-se: Como o turismo e a segunda residência influenciavam na dinâmica urbana da cidade de Portalegre - RN?

Verificou-se que a cidade estava dispondo de uma diversidade de atrativos turísticos, onde o ambiente natural fazia parte e tornava-se o principal desejo dos visitantes e turistas que desejavam sair dos grandes centros, motivando, assim, a aquisição de loteamentos para a construção de segundas residências. Vale salientar, que a cidade estava oferecendo condições naturais, climáticas e territoriais que convidavam o turista a se tornar um consumidor do espaço, já que a segunda residência passou a ser vista como uma opção favorável de lazer ou descanso.

No intuito de destacar a seriedade deste trabalho para a academia, se considera que o mesmo poderá servir de apoio para outras pesquisas que abordem o fenômeno da segunda residência em áreas serranas e que a relacionem à produção e valorização do espaço urbano, contribuindo para o poder público fazer o uso das informações e conduzir as estratégias necessárias ao desenvolvimento urbano, ambiental e turístico da cidade.

\section{SEGUNDA RESIDÊNCIA: ASPECTOS HISTÓRICOS E TEÓRICOS}

Sobre o conceito de segunda residência, um dos primeiros problemas associados refere-se à diversidade das terminologias (segunda residência, residência secundária e alojamentos de uso sazonal), o que dificulta a identificação e caracterização do fenômeno a ser estudado. Contudo, verifica-se que a literatura acadêmica tem feito um uso mais frequente dos termos "segunda residência e residência secundária", que "do ponto de vista conceitual são apreendidos sob a mesma definição", conforme destaca Tulik (2001, p. 113). 
Para Tulik (1995, p. 21) a segunda residência consiste em: "um alojamento turístico particular, utilizado temporariamente, nos momentos de lazer, por pessoas que tem seu domicílio permanente num outro lugar”. Logo o uso desse tipo de domicílio está presente na relação de tempo, custo e distância, uma vez que seus usuários precisam estabelecer certa regularidade entre saídas, chegadas e retornos às cidades de origem e destino.

Corroborando com essa ideia, no seu trabalho empírico, Kaltenborn (1998) ${ }^{1}$, citado por Quinn (2004) identifica outros motivos para a aquisição da segunda residência: a proximidade com a natureza; mudança de vida; descanso físico e mental e estar com a família. Diante do exposto, o processo de decisão de compra do turista é motivado por várias razões que respondem às suas próprias necessidades, desejos e expectativas.

Com efeito, essa prática tem seu uso inspirado por diversos motivos e localizações, fato que justifica a utilização de tipologias a exemplo de casas de férias, casas de verão, casas de fins de semana, casas de praia, casas de campo e casas de temporada.

Estes conceitos encaminham para uma discussão complexa sobre o fenômeno da segunda residência, considerado em grande medida por caráter ideológico e descritivo, orientado particularmente ao estudo da distribuição e dos impactos espaciais. Assis (2003, p. 110) considera como "um tipo de hospedagem vinculada ao turismo de fins de semana e de temporada de férias". O autor aborda três características relacionadas à segunda residência: sendo a primeira a propriedade, a segunda a temporalidade e a terceira a finalidade.

A propriedade tem na renda o fator diferencial, pois enfatiza quem pode possuir uma residência secundária ou não; na qual seu proprietário dispõe de uma renda excedente, pois a aquisição de uma segunda residência implica em custos com a compra do terreno, construção do imóvel, impostos, manutenção e meios de transporte.

A temporalidade marca o uso do domicilio que deve ser ocasional, ou seja, temporário, além de depender da disponibilidade do tempo livre, de renda excedente e da distância do domicílio permanente.

\footnotetext{
${ }^{1}$ KALTHERBORN, B. P. The alternative homes: motives of recreation home use. Norsk Geografisk Tidsskr, p. 121-134, 1998.
} 
Por último, a finalidade, considerada um marco da sociedade "pós-industrial" que tem como sua principal característica a busca da recreação e do gozo do tempo livre, sendo sem dúvida a principal finalidade das construções das segundas residências.

De fato, a caracterização da residência secundária perpassa pela compreensão da oposição à residência principal e do uso temporário por períodos que podem ser prolongados ou não. Ademais, o tempo livre é um dos principais fatores que implicam na aquisição e no uso de um segundo imóvel. Complementando o autor destaca:

\begin{abstract}
Marco da sociedade "pós-industrial", o direito ao tempo livre é uma das grandes conquistas sociais do mundo do trabalho que tem na segunda residência uma das suas modalidades de usufruto. A busca da recreação e do gozo do tempo livre é, sem dúvida, a principal finalidade das construções das segundas residências (ASSIS, 2003, p. 113).
\end{abstract}

Além disso, as ligações afetivas dos proprietários com o lugar e a região, a forma como aproveitam o tempo disponível para o lazer, e a utilização dos equipamentos e serviços oferecidos no destino, são tópicos que ilustram a complexidade sobre a classificação e análise das segundas residências. No que tange à aquisição, existem várias razões para a compra de uma segunda residência. Assim, Hall (2004, p, 12) destaca:

\begin{abstract}
A maioria das famílias compra a segunda residência com o intuito de conseguir alguma dimensão do estilo de vida que não está disponível na sua residência principal. Esta decisão de estilo de vida parece ter uma importância crescente na tomada de decisão da viagem de turismo e lazer incluindo as segundas residências e implica em alguns casos, uma maior mobilidade a nível internacional.
\end{abstract}

Sobre este fato, tendo como estudo no Rio Grande do Norte, o fenômeno da residência secundária tornou-se expressivo no estado com a execução de algumas obras de infraestrutura no decorrer dos anos 1980, conforme Silva (2009, p. 8). Nesse contexto, as cidades têm sido transformadas para atender ao mercado turístico, e esse processo vem gerando a produção de uma nova forma de urbanização definida como urbanização turística, que na concepção de Mullins (1991, p. 331) é conceituada como "uma urbanização que se baseia na venda e no consumo do prazer" (tradução nossa).

A urbanização turística seria aquela que cria toda a infraestrutura necessária à atividade, prevendo e desejando seu desenvolvimento e, muitas vezes, capitalizando o 
espaço para outras práticas, a exemplo da segunda residência. Considerando esse aspecto:

\footnotetext{
Quer na urbanização turística para residências secundárias, quer na urbanização associada a outras modalidades de alojamento turístico, o uso fugaz do território, marcado pela transitoriedade, é responsável por processos de desterritorialização e reterritorialização. O tempo marcado por ritmos planejados (férias, feriados, altas temporadas), impõe um novo ritmo à região, depois recua, e as territorialidades locais se recompõem, mas já sobre outras rugosidades. As regiões, as cidades, os lugares turísticos vestem-se de novas materialidades: galerias, shopping centers, edificações, condomínios fechados, infraestrutura viária e uma infinidade de objetos e serviços especializados para o turismo (LUCHIARI 1998, p. 24).
}

De acordo com a ideia de Luchiari, a atividade turística e a segunda residência apresentam significativa influência no processo de reprodução do espaço. Por mais que o urbano não possa ser explicado, de forma exclusiva, por essas práticas, é com base nelas que se justifica, em muitos casos, o ordenamento do território. Assim, evidenciase que o município de Portalegre-RN apesar de não ter uma proposta prática de desenvolvimento turístico e urbanístico, segundo Fernandes (2008. p. 93) vivenciou momentos de fomento ao turismo, destacadamente, a partir do ano 2000 impulsionando, por conseguinte, a reprodução do espaço urbano local, em consórcio com o setor imobiliário.

\subsection{TURISMO E SEGUNDA RESIDÊNCIA NA CONSTRUÇÃO DO ESPAÇO URBANO}

Conforme visto, uma segunda residência requer uma estruturação urbana, que muitas vezes encontra respaldo, também no turismo, tendo em vista, que podem dinamizar a economia de um local e contribuir para a revalorização do espaço natural e urbano, incentivando também a permanência da população local e atraindo novos fluxos.

É importante salientar que o turismo, assim como uma segunda residência, produz e consume espaço, e que dentre outras funções, tem como foco o aspecto econômico que vem definindo a atividade em todo o mundo, muito embora se reconheça a necessidade de abordagem de outros aspectos que influenciam na produção do espaço, muitos deles expressos por elementos sociais, culturais, políticos e 
ambientais que traduzem a forma de ser dos lugares, dando identidade e singularizandoos. Contudo, entende-se que o desenvolvimento da atividade turística requer a implementação de uma infraestrutura urbana adequada, que promova a expansão da atividade e a melhoria dos produtos ofertados.

Nesse sentido, o poder público deve atuar como mediador de modo que proporcione a organização e reprodução do capital, bem como, a melhoria das condições de vida da população, gerenciando os conflitos e contradições que venham impedir tal dinâmica. Associado a essa pressão, existe também um mercado de terras onde atuam diversos agentes (o Estado, o proprietário e o promotor imobiliário) com diferentes objetivos, originando em alguns casos conflitos econômicos e territoriais no processo de planejamento e ordenamento.

Nesse sentido, Fratucci (2009, p. 6) afirma que o turismo, em sua prática, provoca uma nova organização de um território produzindo um espaço para a atividade turística. Deste modo, a presença das infraestruturas, equipamentos e serviços são necessários nos espaços, quer sejam emissores, receptores e de deslocamentos.

Assim, a demanda por infraestrutura urbana cresce significativamente, uma vez que o turismo se utiliza dessa dinâmica urbana para o seu funcionamento. Segundo Beni (1997, p. 128), o diagnóstico da infraestrutura de um núcleo receptor, de um polo de desenvolvimento, ou de um centro de polarização de turismo, deve incluir os serviços urbanos, que na concepção desse autor são:

\footnotetext{
Todos aqueles serviços que competem às atividades-fim do setor público, ou seja, de competência da administração municipal, indispensável igualmente à qualidade de vida e a todo empreendimento habitacional ou empresarial que venha a ser implantado. São: Energia e iluminação pública; limpeza pública; transporte coletivo; comunicações; abastecimento; conservação de logradouros públicos; controle da poluição da água e do ar; equipamentos e serviços de infraestrutura do turismo.
}

Ademais, com o intuito de promover um desenvolvimento mais igualitário, e minimizar vários dos problemas urbanos encontrados nas cidades, foi criada no ano de 2001 a Lei 10.257, propondo o Estatuto das Cidades que visa estabelecer "as diretrizes gerais da política urbana objetivando principalmente o pleno desenvolvimento das funções sociais da cidade e a garantia ao direito a cidades sustentáveis." (BRASIL, 2001, p. 9). 
A partir disso, surge o Plano Diretor que estabelece diretrizes para o esporte, lazer, moradia, comércio, entre outros equipamentos urbanos, públicos ou privados que necessitam de planejamento para sua adequação e uso. (RIBEIRO, 2013. p. 913). Além disso, os planos diretores municipais têm relevância na interferência da imagem das cidades, uma vez que os mesmos buscam estruturar os ambientes para que estes venham melhor atender as necessidades dos seus usuários, sendo instrumentos obrigatórios apenas para os municípios acima de 20 mil habitantes.

Nesse caso, um plano diretor define o caminho a ser seguido, principalmente, através do estabelecimento de princípios, diretrizes e normas, fornecendo orientações para as ações que influenciam no desenvolvimento urbano. Essas ações podem ser desde a abertura de uma nova avenida, construção de uma nova residência, ou a implantação de uma estação de tratamento de esgoto. É importante também que estratégias de atuação sejam definidas para as ações do Poder Público, já que essas ações são fundamentais para qualquer cidade.

No entanto, em sua relação com o turismo a transformação do espaço urbano não deve ser entendida como uma mera consequência dos processos de apropriação, consumo e produção do espaço, ela é uma necessidade básica para o desenvolvimento dessa atividade. "A atratividade dos lugares (paisagens naturais ou construídas) precisa ser constantemente vendida, logo, ela é recriada, padronizada em estilo, estética e atendimento" (LUCHIARI, 1998, p. 24).

Desse modo, a imagem de uma cidade tem um papel relevante para muitas atividades, especialmente para a atividade turística, já que envolve a percepção dos residentes sobre o desenvolvimento estético do espaço urbano, bem como, a maior procura de pessoas pelo destino e o ordenamento de suas práticas.

A cidade é socialmente instrumentalizada para responder à nova disciplinarização dos corpos, constituída pelo jogo caótico de imagens simulacionais e pelo aprofundamento da fragmentação social do/no espaço. A retificação das relações sociopolíticas se reproduz nas cidades como expressão do fetichismo de um mundo convertido em imagens espetaculares. Imagens que se banalizam e logo se degeneram no ato de sua difusão massificante, para serem imediatamente substituídas com o mesmo teor generalizante da ilusão de um presente perpétuo, apesar de efêmero. A imagem clichê da desordem como recurso mimético de ordenamento territorial da cidade institui-se para desativar a potencialidade social das lembranças, pois a lógica fragmentária da desordem encerra a imaginação em passagens labirínticas e se impõe com o apagar da memória social depositada nas ruas, nas fachadas dos prédios, jardins, praças, becos e vãos que compõem o complexo mosaico das cidades (BARBOSA, 2007, p. 131). 
A construção da imagem citadina orienta, dessa forma, toda a dinâmica urbana, principalmente, quando a dinâmica é norteada pela forma de planejamento estratégico que transforma o espaço urbano em mercadoria. Assim, como expressa Gândara (2001. p. 308) "só existirá qualidade na imagem, uma vez que exista qualidade no ambiente, e este seja percebido pelo usuário da cidade".

Nesse caso, toda cidade acaba sendo o reflexo da forma de pensar das pessoas que nelas vivem, onde a dinâmica dos espaços urbanos, bem como, suas características de singularidade e de local de encontro, acaba transformando as cidades em locais de interesse turístico, com níveis variados de motivação. Além do exposto, é importante ressaltar que o poder público tem papel relevante nessa imagem, haja vista, que suas ações de ordenamento do território têm influência direta sobre a mesma. Considerando essa contextualização, faz-se necessário destacar que:

O planejamento urbano não deve ser pensado por uma visão estritamente física que priorize a ordenação do território, sua configuração arquitetônica, seus equipamentos coletivos, mas sim proporcionar um ambiente que possa possibilitar construir cidadania em seus habitantes (GÂNDARA, 2001, p. $383)$.

Como descrito pelo autor, em sua relação com o turismo, o planejamento urbano deve ser trabalhado com o objetivo de proporcionar a criação de valor para o destino turístico, na qual, o turista deve adquirir juntamente com os serviços, a experiência e a sensação de uma cidade estruturada. Para isso, deve-se adotar uma relação de atrativos e de caminhos para que a experiência vivida pelo turista seja a mais agradável possível.

Com essas abordagens, considera-se, ter ficado visível que as cidades são espaços de encontros, de convivências e de história, cada qual com suas singularidades fruto da ocupação e produção espacial, e possuem atratividades diversas que motivam suas visitações, mas para isso, devem ser locais adequados ao convívio em sociedade, apresentando qualidades sociais, culturais e ambientais que atendam às necessidades da população e estimulem a visitação.

Nesse contexto, tanto o conceito de "desenvolvimento sustentável do turismo" quanto o de "consumo responsável do turismo" são vistos como respostas que determinam o grau de solidez para que se favoreça um melhor planejamento e gerenciamento dessa atividade. (MAMEDE, 2003, p. 148). 
Como visto a atividade turística e as segundas residências apresentam significativa influência no processo de reprodução do espaço. Por mais que o urbano não possa ser explicado, de forma exclusiva, por essas práticas, é com base nelas que se justifica, em muitos casos, o ordenamento de um território.

Assim, evidencia-se o município de Portalegre-RN que apesar de não ter uma proposta de desenvolvimento turístico e urbanístico efetivo, o mesmo vivenciou momentos de fomento ao turismo, destacadamente, a partir do ano 2000, impulsionando, por conseguinte, a reprodução do espaço urbano local, em consórcio com o setor imobiliário em período mais recente.

\subsection{AS MUDANÇAS NO ESPAÇO TURÍSTICO DA CIDADE DE PORTALEGRE EM DECORRÊNCIA DO USUFRUTO DAS SEGUNDAS RESIDÊNCIAS}

A partir da abordagem teórica, realizou-se o trabalho empírico e aplicação de formulários aos proprietários de segundas residências. Na ocasião, foram identificadas 16 residências com os proprietários presentes no momento da entrevista.

Para que as atividades turísticas sejam realizadas de modo a promover o melhor desenvolvimento possível de um destino, é essencial entender como os consumidores tomam as suas decisões para adquirir ou utilizar os produtos turísticos, no presente caso, compreender as motivações das pessoas que se interessavam pelas segundas residências em cidades serranas.

\footnotetext{
O processo de decisão de compra do turista surge com a necessidade que se traduz em motivações turísticas gerando no consumidor a busca de informação que permite avaliar as diferentes alternativas para satisfazer as suas necessidades. A natureza deveras particular que envolve as motivações faz com que alguns investigadores distinguem diversos tipos de turistas com diferentes motivos básicos, o que pode estar relacionado com a personalidade e estilo de vida de cada indivíduo (COBUCI, 2008, p. 128).
}

De acordo com Hall e Müller (2004, p. 453), existem várias razões para comprar uma segunda residência. E a maioria das famílias compra a segunda residência com o intuito de conseguir alguma dimensão do estilo de vida que não está disponível na sua residência principal. 
Sendo assim, traçando um perfil dos entrevistados constatou-se que 8 (oito) deles situavam-se na faixa etária entre 46 a 60 anos de idade; aposentados; do gênero masculino; casados; e com filhos. Além disso, 13 (treze) possuíam nível superior completo e estavam empregados em atividades ligadas ao setor privado e público, com uma renda familiar mensal que ultrapassava dez salários mínimos.

Tais características compõem de fato o perfil daquelas pessoas que optam por uma segunda residência. Tomando como referência os recursos financeiros, Cólas (2003, p. 21) destaca que esse elemento é imprescindível tanto para o turismo como para a prática da aquisição de uma segunda residência, evidenciando, que ainda são privilégios de poucos.

Assim, ao questionar os entrevistados sobre o local de residência permanente, verificou-se que a grande maioria era da cidade de Pau dos Ferros-RN, seguida de 4 (quatro) da cidade de Riacho da Cruz-RN, 4 (quatro) da cidade de Natal-RN e 3 (três) do estado de São Paulo-SP, evidenciando, portanto, a necessidade de proximidade com a residência primária, conforme destacada na discussão teórica dessa pesquisa.

Na abordagem, Jaakson (1986, p. 13) "defende que existe uma distância psicológica mínima que separa a residência principal da segunda residência e essa distância funciona como um fator de motivação para deixar a primeira residência e seguir viagem para a outra casa que está fora da cidade".

No que tange ao tempo de posse da segunda residência, verificou-se que a maioria, dos entrevistados já possuía a residência há algum tempo entre 6 e 10 anos e que 5 (cinco) deles, tiveram a intenção inicial ao adquirir o imóvel devido a tranquilidade do lugar, enquanto outros 5 (cinco) optaram pelo destino com intuito apenas de lazer. 
FIGURA 1 - CASA DE SEGUNDA RESIDÊNCIA MAIS ANTIGA DA CIDADE DE PORTALEGRE/RN

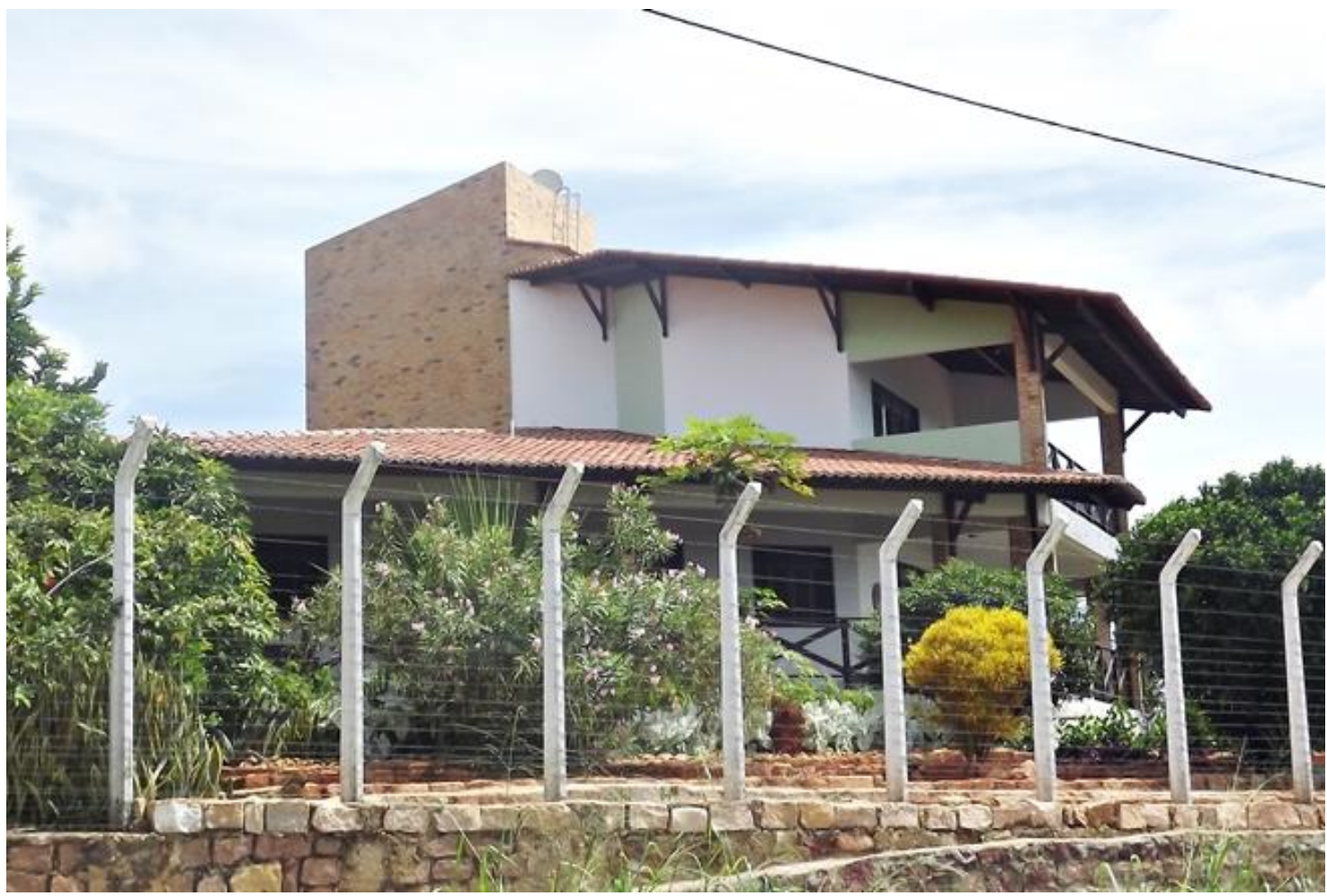

FONTE: Costa (2014).

A figura 1, a título de ilustração, representa a mais antiga das casas de segunda residência na cidade, construída há mais de 10 anos verificando-se servir apenas para o descanso do proprietário que estava tendo residência permanente em Natal-RN. Enfatiza-se então que o quadro que marca o início dessa prática coincide com o contexto de desenvolvimento da atividade turística que, de certa forma, teve um importante papel no sentido da divulgação do município.

Este tipo de turismo deve ser entendido como propulsor do desejado efeito multiplicador na economia regional, quando promovido na ótica do desenvolvimento sustentável. "Se isso não acontece, pode igualmente apresentar-se como algo problemático, indutor de impactos negativos que tem a especulação imobiliária como exemplo" (MANTECÓN, 2008, p. 126).

No tocante à localização das casas, percebeu-se que a escolha se deu em razão da tranquilidade do local, bem como da proximidade com elementos e atrativos naturais como: fonte da bica, trilhas e mirantes, indicados por 8 (oito) pessoas. Assim, muitas 
dessas residências foram construídas na entrada ou na saída da cidade, bem como próximas aos locais com exuberância natural e aos atrativos turísticos mais visitados.

Essas últimas, em consonância com a exploração turística, se tornaram responsáveis por ratificar o aumento do valor de uso do solo urbano, fato constatado no preço do metro quadrado nas proximidades que estava custando em média $\mathrm{R} \$ 100,00$ (cem reais), enquanto que em outros locais mais distantes dos atrativos e das amenidades naturais, o metro quadrado poderia ser adquirido por $\mathrm{R} \$ 60,00$ (sessenta reais). As experiências rurais e naturais têm expressão na motivação pela escolha do local de uma segunda residência, haja vista, serem ausentes no contexto urbano, onde normalmente, estão localizadas as residências primárias desses proprietários.

Verificou-se, também, por ocasião da pesquisa, que 6 (seis) turistas que possuíam a segunda residência optavam ir ao município semanalmente ou mensalmente e outros 3 (três) pela distância com o destino anualmente, já 1 (um) precisava ir diariamente por causa de algum vínculo empregatício ligado com o poder público na cidade. Mas foi notório que a frequência de visita ao município era mais acentuada nos feriados, tanto por causa de residirem em cidades próximas e conhecerem mais de perto a realidade do município, como pela oportunidade de descanso e lazer com a família.

Os turistas viajam com destino às suas segundas residências na sexta-feira à noite, após a jornada de trabalho semanal ou na manhã do sábado, aproveitando assim, o final de semana e retornando, geralmente à tarde do domingo às suas residências permanentes. "Esses fatores podem contribuir para a valorização de recursos naturais e culturais mais próximos dos centros emissores que são preferidos a outros, de qualidade superior, porém, mais distantes" (TULIK, 1998, p. 202). No entanto, podem ser sintetizados nas três categorias sugeridas:

\footnotetext{
Saber: gestão de identidade (contraste com a vida quotidiana moderna, símbolo de status); função recreativa e intelectual "manutenção psicológica" (contato com a natureza e as redes sociais); e razões pragmáticas (que se relacionam com a fase da vida, existência e idade das crianças, calendários de feriados, investimento de capital). (QUINN, 2004, p. 116).
}

Em consonância com esse contexto, constatou-se na pesquisa que na visita à cidade, geralmente os 11 (onze) proprietários vinham acompanhados de seus familiares. Contudo, observou-se que 7 (sete) dos parentes mais presentes era a esposa ou o 
marido. Em outras situações, quando o turista não viajava só, costumava sempre levar os filhos ou amigos para conhecer a cidade.

Os atrativos mais procurados durante a visita foram os equipamentos e serviços de lazer como: O Mirante Boa Vista e o Mirante Recanto Alto da Serra que por sinal ficavam próximos um do outro e possuíam uma visão privilegiada da serra. Em relação aos outros atrativos visitados com menor frequência vale destacar: o Terminal Turístico da Bica, a Cachoeira do Pinga logo no início da serra, a Trilha das Duas Torres e da Pedra do Letreiro com inscrições rupestres. Esses últimos ainda estavam sendo pouco visitados em razão da ausência de acessibilidade e infraestrutura. Outros, optavam por até mesmo não sair da residência.

Em relação às festividades locais, percebeu-se que o tradicional São João na Serra realizado no mês de junho, foi o mais escolhido por 10 (dez) entrevistados, seguido do Retiro Evangélico realizado no mês de fevereiro com 3 (três) menções e da Festa da Padroeira Nossa Senhora da Conceição no mês de dezembro com 3 (três) indicações.

Essas características evidenciaram o que vem sendo discutido em muitos trabalhos que entendem a segunda residência como uma prática também turística, haja vista os residentes visitarem muitos dos equipamentos e atrativos turísticos da localidade. A título de exemplo, Tulik (2001, p. 12) "concebe as segundas residências enquanto alojamento turístico, ou seja, aqueles imóveis que são utilizados com finalidades de lazer, por períodos de fins de semana e/ou férias, tendo como característica o deslocamento".

Nessa perspectiva, a hospedagem passa a ser utilizada para os momentos de lazer e recreação, mas levando em consideração que o proprietário não deixa de interagir e participar do lazer promovido na cidade receptora.

A maioria dos entrevistados também mencionou usufruir dos serviços básicos como: abastecimento de água, energia e coleta de lixos oferecidos pelo município, pois a casa de segunda residência mantém os mesmos padrões da residência principal e como, geralmente mencionaram passar mais de um dia no município, necessitavam utilizar serviços variados que compõem tanto a infraestrutura urbana como a turística.

Ainda com base nas informações dadas, vale destacar os serviços de abastecimento de combustível, comunicação, saúde, alimentação, financeiro, segurança, 
lazer dentre outros que acabam por demandar uma oferta ampliada, contribuindo para uma dinâmica urbana no âmbito do município. Sobre a avaliação da atuação do poder público em relação às atividades turísticas e de infraestrutura urbana desenvolvidas no município, 8 (oito) turistas que contribuíram com a pesquisa consideraram como péssima e 6 (seis) ruim e somente 3 (três) avaliaram como boa essas atividades.

Sobre a escolha de ter uma segunda residência no município de Portalegre, os entrevistados afirmaram que a cidade tinha um potencial turístico relevante, mas que precisava melhorar muito, faltando principalmente investir na cultura local, na limpeza urbana e na recuperação de prédios histórico. Conforme constatado, percebeu-se uma significativa fragilidade no que tange à manutenção de prédios, equipamentos turísticos e os investimentos na área que pudessem atender a uma demanda turística que estava se mantendo expressiva, sinalizando de fato para um crescimento, com o aumento da ocorrência de residências secundárias no município.

Além das casas de segunda residência evidenciadas na cidade, constatou-se que muitas pessoas optaram, também pela escolha de Loteamentos, destes o Varandas da Serra era o único que se encontrava em comercialização. Na oportunidade, no mesmo dia da entrevista com os turistas de segunda residência também foi realizada uma entrevista com a auxiliar de escritório da MN imóveis, empresa responsável pelas vendas do loteamento no município e na Região Oeste. Segundo ela, existia apenas o loteamento chamado de Varandas da Serra, figura 2 que iniciou as vendas em 3 de novembro de 2012. 
FIGURA 2 - MAPA DE LOCALIZAÇÃO DO LOTEAMENTO VARANDAS DA SERRA

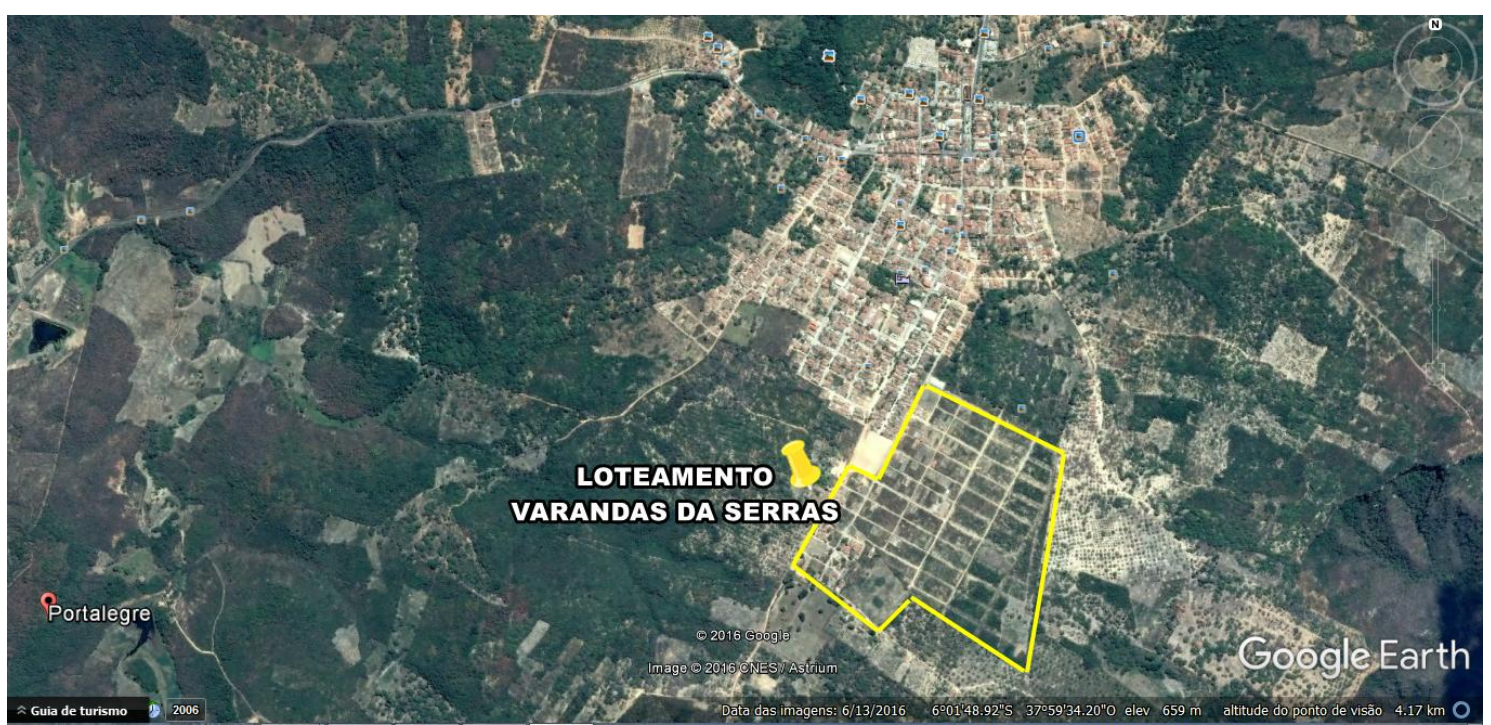

FONTE: Google Earth, setembro (2013).

O nome do loteamento foi inspirado na tranquilidade do lugar e na possibilidade de maior contato com a natureza, características que se associam às motivações apontadas na pesquisa pelos proprietários de segunda residência que foram entrevistados. O loteamento estava localizado num terreno alto, ventilado e plano, localizado na Rua Antônio Ribeiro de Bessa, bairro da COHAB - Companhia de Habitação Popular, próximo ao campo de futebol.

A auxiliar afirmou que não sabia ao certo quantos lotes já haviam sido vendidos, mas assegurou que a maior procura ocorria nos meses de novembro, dezembro e janeiro quando o município recebia um maior número de visitantes. Por consequência, a falta de maior disponibilidade financeira e o tempo livre para o aproveitamento das férias com a família, torna-se com a segunda residência uma importante alternativa de lazer, devido à economia de tempo e de trabalho e, sobretudo dinheiro.

Para Michaud² (apud SONERO, 1991, p. 151) a residência secundaria "[...] é, sobretudo um investimento rentável, como comprovam os fatores fundamentais: seu escasso índice de frequentação, pois permanecem vazias a maior parte do ano, e o escasso tempo, que geralmente, pertencem ao mesmo proprietário [...]". Todavia, Tulik (1995, p. 154) adverte que residência secundaria “[...] é um investimento que não oferece liquidez e nem rentabilidade imediatas, pois a venda está sujeita às leis de oferta

${ }^{2}$ MICHAUD, Y. A violência. Tradução de L. Garcia. São Paulo: Ática, 1986. 
e procura nem sempre estes imóveis são alugados, permanecem vazios na maior parte do ano".

Questionada sobre o desenvolvimento da infraestrutura na cidade, a auxiliar da MN Imóveis afirmou que algumas ruas foram abertas, assim, como a pavimentação de outras próximas ao local, mas nada que pudesse agregar valor de forma mais efetiva. Que existiam no caso apenas projetos, com construção de duas praças, uma igreja e um ginásio, mas que ainda não haviam saído do papel.

Outro ponto importante, observado por ocasião da pesquisa, diz respeito ao fato de que muitas famílias residentes no município estavam possuindo lotes de terras sem construção, alguns em processo de especulação e outros sendo vendidos por valores mais altos que os adquiridos, evidenciando, portanto, a valorização do uso do solo nos últimos anos, fato que também, estava sinalizando para a dinamização urbana do município que estava se processando com a ajuda de um mercado imobiliário ainda com frágil expansão, mas com potencial significativo.

\section{CONCLUSÃO}

A presente pesquisa permitiu analisar a segunda residência como segmento relevante na dinâmica urbana e turística do município de Portalegre-RN. Onde foi perceptível que essas práticas estavam suscitando repercussões no espaço urbano e sendo potenciais para ampliar o setor econômico e contribuir com o aumento da valorização territorial e dos atrativos no entorno.

No entanto, observou-se, que após o ano de 2012, marco da transição de gestão pública poucos investimentos públicos foram registrados, fato ratificado, inclusive pela extinção da Secretaria Municipal de Turismo e da Secretaria Municipal de Obras e Urbanismo. Nesse sentido, a reprovação da gestão, por parte dos proprietários de segunda residência foi bastante expressiva, tendo em vista que a maior parte dos entrevistados considerou a atuação do poder público como ruim ou péssima.

Vale salientar, no que pese as fragilidades encontradas, que os fluxos turísticos continuavam e que a dinâmica proporcionada pela segunda residência estava permanecendo sob a justificativa da procura de tranquilidade e opções de lazer ofertadas 
no município. Nesse contexto, vale salientar ter-se constatado que a cidade estava oferecendo condições naturais, climáticas e territoriais que prevaleciam na escolha do visitante, tornando-o um importante agente de produção do espaço urbano local.

Conforme visto, as segundas residências necessitavam de uma infraestrutura urbana, que muitas vezes encontrava suporte no segmento do turismo. E a apropriação no espaço por essa prática estava provocando diversificadas mudanças sociais e espaciais, que acabavam dinamizando a economia local, além de revalorizar o espaço natural e urbano, facilitando a permanência dos residentes e atraindo consequentemente novos fluxos de turistas ao município.

Para finalizar, conclui-se que os objetivos da pesquisa foram alcançados, visto que os aspectos históricos e teóricos sobre Segunda Residência foram apresentados no sentido de familiarizar-se com a temática, além de constatar que os investimentos realizados ao longo dos anos pelo poder público foram primordiais para iniciar o desenvolvimento do turismo, e consequentemente promover as mudanças no espaço turístico, a partir das instalações de segundas residências.

Partindo desse pressuposto, constatou-se que a atividade turística destinada a segunda residência era viável de ser explorada no âmbito deste município, uma vez que trouxe benefícios financeiros para o mesmo, gerando emprego e renda para os munícipes. Conclui-se assim, que o Poder Público local precisava tomar consciência de que a exploração do turismo era de fundamental importância para o desenvolvimento local. Portanto, a pesquisa não se esgota nessa discussão, considerando que ainda é recente de investigações e possui novas características e conceitos que podem ser inseridos para embasar os estudos e auxiliar pesquisadores na área.

\section{REFERÊNCIAS}

ASSIS, L. F. de. Turismo de segunda residência: a expressão espacial do fenômeno e as possibilidades de análise geográfica. Revista Território, Rio de Janeiro, ano 7, n. 11, 12 e 13 , set. Out. 2003.

BARBOSA, J. L. O ordenamento territorial urbano na era da acumulação globalizada. In: Território, territórios: ensaios sobre o ordenamento territorial. SANTOS, M. et al. 3. ed. Rio de Janeiro: Lamparina, 2007. 
BENI, M. C. Análise estrutural do turismo. 10. ed. São Paulo: Editora SENAC - SP, 1997.

BRASIL. Estatuto da Cidade: guia para implementação pelos municípios e cidadãos. Brasília: Câmera dos Deputados, Coordenação de Publicações, 2001. Disponível em: <http://www.bage.rs.gov.br/pddua/estatuto/pddua_estatuto.pdf $>$. Acesso em: 26/06/2014.

CASCUDO, L. da C. História do Rio Grande do Norte. 2. ed. Natal: Fundação José Augusto. Rio de Janeiro: Achaiamé, 1984.

COLÁS, J. L. La residencia secundaria en España: estúdio territorial de uso y tenência. Barcelona. Tese (Doutorado em Geografia). Facultat de Filosofia i Lletres. Universitat Autônoma de Barcelona, 2013.

COBUCI, L. O Concelho de Ílhavo enquanto destino do turismo residencial - Caso de estudo: Praias da Barra e Costa Nova. Tese de Mestrado, Universidade de Aveiro, Portugal, 2008.

COSTA. A. J. da. Turismo e Segunda Residência na Dinâmica Urbana da cidade de Portalegre-RN. Monografia (Graduação em Turismo). Mossoró, Universidade do Estado do Rio Grande do Norte - UERN, 2014.

FRATUCCI, A. C. Refletindo Sobre a Gestão dos Espaços Turísticos: perspectivas para as redes regionais de turismo. Turismo em Análise, v. 20, n. 3, dezembro 2009, p. 391-408.

FERNANDES, M. de F. D. Turismo, Políticas Públicas e Desenvolvimento Local: um Estudo da Atividade Turística no Município de Portalegre-RN, no Período de 2001 a 2008. Pau dos Ferros, UERN. Ano 2008, p. 93.

GÂNDARA, J. M. G. La imagen de calidad ambiental urbana como recurso turístico: el caso de Curitiba. Tese (Doutorado em Turismo e Desenvolvimento Sustentável) - Universidad de Las Palmas de Gran Canaria. Las Palmas de Gran Canaria, Brazil. 2001. 471 fl.

Google Earth. Downloads Área de Trabalho. Localização do Loteamento Varandas da Serra em Portalegre, Rio Grande do Norte. Disponível em: <https://www.google.com/earth/>. Acesso em: 02/09/2013.

$\begin{array}{lrrrrr}\text { IBGE. INSTITUTO } & \text { BRASILEIRO DE } & \text { GEOGRAFIA } & \text { E } & \text { ESTATÍSTICA. } & \text { Perfil } \\ \text { Municipal } & - & \text { Portalegre } & (\mathbf{R N}) . & \text { Disponível } & \text { em: }\end{array}$ $<$ http://www.cidades.ibge.gov.br/xtras/perfil.php?lang=\&codmun=241020\&search=riogrande-do-norte|portalegre $>$. Acesso em: 19/05/2010.

JAAKSON, R. Second home domestic tourism. Annals of Tourism Research, v. 13, 1986, p. 367-391. 
LUCHIARI, M. T. D. P. Urbanização turística: um novo nexo entre o lugar e o mundo. In: LIMA, L. C. (Org.). Da cidade ao campo: a diversidade do saber fazer turístico. Fortaleza: UECE, 1998.

MANTECÓN, A. La experiencia del turismo. Un estudio sociológico sobre el proceso turístico-residencial. Barcelona: Icaria, 2008.

MAMEDE, V. S. M. D. Participação e desenvolvimento do turismo local. In: MARTINS, C. (Organizador). Turismo, cultura e identidade. São Paulo: Roca, p. 31$38,2003$.

MULLINS, P. Tourism urbanization. International Journal of Regional Research, 15 (3): p. 326-342, 1991.

QUINN, B. Dwelling through multiple places: a case study of second home ownership in Ireland In: HALL; MÜLLER (Eds.). Tourism Mobility and Second Homes. Between Elite Landscape and Common Ground. Clevedon: Channel View Publications, 2004, p. 113-130.

RIBEIRO, R. M. Planos Diretores, Perspectiva Legal e Organização do Território para o Turismo. In: Turismo \& Sociedade. (ISSN: 1983 -5442). Curitiba, v. 6, n. 4, p. 911915, outubro de 2013.

SILVA, K de O. Condomínios fechados, residências secundárias e o uso do espaço público pelo capital imobiliário. Observatório de Inovação do Turismo - Revista Acadêmica. v. IV, n. 1, março de 2009.

SONEIRO, J. C. Aproximación a la geografía del turismo. Madrid: Sintesis. 1991, p. 151. In: Revista Território, Rio de Janeiro, Ano VII, n. 11, 12 e 13, set./out., 2003, p. 107-122.

TULIK, O. Turismo e meios de hospedagem: casas de temporada. São Paulo: Roca, 2001.

O espaço aberto à segunda residência. In: LIMA, L. C. (org.). Da cidade ao campo: diversidade do saber-fazer turístico. Fortaleza: UECE, 1998.

Residências secundárias: presença, dimensão e expressividade do fenômeno no Estado de São Paulo. Tese de livre docência - Escola de Comunicação e Artes, Universidade de São Paulo, São Paulo, 1995.

Recebido em: 10-11-2016.

Aprovado em: 10-12-2016. 